\title{
Note on currencies and translations
}

\begin{tabular}{ll}
\hline 1 Reichsthaler (rt.) & $=90$ Kreuzer \\
1 Gulden (gl.)/Florin (fl.) & $=60$ Kreuzer \\
$=240$ Pfennige & 1 Kopffstück \\
& $=20$ Kreuzer \\
1 Kreutzer (kr.) & $=4$ Pfennige \\
1 Pfennig (dl.) & $=2$ Heller \\
1 Gulden (gl.) & $=£ 03 \mathrm{~s} \mathrm{0d}$ \\
\hline
\end{tabular}

Unless otherwise noted, all translations are my own. 